\title{
Long-Term Effects of an Internet-Mediated Pedometer-Based Walking Program for Chronic Obstructive Pulmonary Disease: Randomized Controlled Trial
}

Marilyn L Moy ${ }^{1,2}$, MD; Carlos H Martinez ${ }^{3}$, MD; Reema Kadri ${ }^{4,5}$, MLIS; Pia Roman ${ }^{5}$, MA; Robert G Holleman ${ }^{5}$, MPH; Hyungjin Myra Kim ${ }^{5,6}$, ScD; Huong Q Nguyen ${ }^{7}, \mathrm{PhD}$; Miriam D Cohen ${ }^{8}$, MSN; David E Goodrich ${ }^{5}$, EdD; Nicholas D Giardino ${ }^{9}, \mathrm{PhD}$; Caroline R Richardson ${ }^{4,5}, \mathrm{MD}$

\footnotetext{
${ }^{1}$ Pulmonary and Critical Care Medicine Section, VA Boston Healthcare System, Boston, MA, United States

${ }^{2}$ Harvard Medical School, Boston, MA, United States

${ }^{3}$ Pulmonary \& Critical Care Division, University of Michigan Health System, Ann Arbor, MI, United States

${ }^{4}$ Department of Family Medicine, University of Michigan, Ann Arbor, MI, United States

${ }^{5}$ Center for Clinical Management Research, VA Ann Arbor Healthcare System, Ann Arbor, MI, United States

${ }^{6}$ Department of Biostatistics, School of Public Health, University of Michigan, Ann Arbor, MI, United States

${ }^{7}$ Department of Research and Evaluation, Kaiser Permanente Southern California, Pasadena, CA, United States

${ }^{8}$ Pulmonary Medicine Section, VA New York Harbor, Brooklyn, NY, United States

${ }^{9}$ Department of Psychiatry, University of Michigan, Ann Arbor, MI, United States
}

\section{Corresponding Author:}

Caroline R Richardson, MD

Department of Family Medicine

University of Michigan

1018 Fuller St.

Ann Arbor, MI, 48104

United States

Phone: 17349987120 ext 316

Fax: 17349987335

Email: caroli@umich.edu

\section{Abstract}

Background: Regular physical activity (PA) is recommended for persons with chronic obstructive pulmonary disease (COPD). Interventions that promote PA and sustain long-term adherence to PA are needed.

Objective: We examined the effects of an Internet-mediated, pedometer-based walking intervention, called Taking Healthy Steps, at 12 months.

Methods: Veterans with COPD $(\mathrm{N}=239)$ were randomized in a 2:1 ratio to the intervention or wait-list control. During the first 4 months, participants in the intervention group were instructed to wear the pedometer every day, upload daily step counts at least once a week, and were provided access to a website with four key components: individualized goal setting, iterative feedback, educational and motivational content, and an online community forum. The subsequent 8-month maintenance phase was the same except that participants no longer received new educational content. Participants randomized to the wait-list control group were instructed to wear the pedometer, but they did not receive step-count goals or instructions to increase PA. The primary outcome was health-related quality of life (HRQL) assessed by the St George's Respiratory Questionnaire Total Score (SGRQ-TS); the secondary outcome was daily step count. Linear mixed-effect models assessed the effect of intervention over time. One participant was excluded from the analysis because he was an outlier. Within the intervention group, we assessed pedometer adherence and website engagement by examining percent of days with valid step-count data, number of log-ins to the website each month, use of the online community forum, and responses to a structured survey.

Results: Participants were 93.7\% male (223/238) with a mean age of 67 (SD 9) years. At 12 months, there were no significant between-group differences in SGRQ-TS or daily step count. Between-group difference in daily step count was maximal and statistically significant at month $4(P<.001)$, but approached zero in months 8-12. Within the intervention group, mean $76.7 \%$ (SD 29.5) of 366 days had valid step-count data, which decreased over the months of study $(P<.001)$. Mean number of log-ins 
to the website each month also significantly decreased over the months of study $(P<.001)$. The online community forum was used at least once during the study by $83.8 \%$ (129/154) of participants. Responses to questions assessing participants' goal commitment and intervention engagement were not significantly different at 12 months compared to 4 months.

Conclusions: An Internet-mediated, pedometer-based PA intervention, although efficacious at 4 months, does not maintain improvements in HRQL and daily step counts at 12 months. Waning pedometer adherence and website engagement by the intervention group were observed. Future efforts should focus on improving features of PA interventions to promote long-term behavior change and sustain engagement in PA.

ClinicalTrial: Clinicaltrials.gov NCT01102777; https://clinicaltrials.gov/ct2/show/NCT01102777 (Archived by WebCite at http://www.webcitation.org/6iyNP9KUC)

(J Med Internet Res 2016;18(8):e215) doi: 10.2196/jmir.5622

\section{KEYWORDS}

bronchitis, chronic; emphysema; pulmonary disease, chronic obstructive; quality of life; exercise; motor activity; Internet

\section{Introduction}

Physical activity (PA) is significantly reduced in persons with chronic obstructive pulmonary disease (COPD), even at the earliest stages of disease [1-3]. Its clinical course is punctuated with acute exacerbations, during and following which persons suffer further reductions in PA [4,5]. As a disease with systemic consequences, COPD increases vulnerability to frailty, immobility, and loss of functional independence. Despite optimal pharmacological therapy, persons with COPD suffer from a downward spiral of breathlessness, deconditioning, and physical inactivity [6]. Comorbidities of cardiovascular disease, diabetes mellitus, and osteoporosis contribute to further reductions in PA [7,8].

Physical activity is a modifiable health behavior that affects COPD-specific outcomes [9-14]. It has been shown that a greater quantity of low-intensity PA reduces risk of COPD hospitalizations, whereas high-intensity PA does not result in risk reduction [15]. In a cohort of persons with COPD, those who walk the least have risks that are 2 and 6 times higher for acute exacerbations and COPD-related hospitalizations, respectively, compared to those who walk the most [12]. In addition, persons with COPD with higher PA levels have a significantly lower risk of dying, independent of forced expiratory volume in 1 second $\left(\mathrm{FEV}_{1}\right)$ [14]. The Global Initiative for Chronic Obstructive Lung Disease (GOLD) guidelines recommend regular PA for all persons with stable COPD as part of standard nonpharmacological treatment [6].

Despite the evidence and recommendations, effective long-term PA interventions are lacking in the clinical care of patients with COPD. Most studies of long-term exercise interventions have examined methods to maintain exercise in the subset of persons with COPD who have completed a conventional pulmonary rehabilitation program [16-21]. These interventions have combined weekly- or monthly-supervised exercise classes with unsupervised home exercise, support groups, and/or telephone contact with a health care professional, showing mixed results over the long term [16-21]. Strategies that promote behavior change and long-term adherence to effectively sustain PA in all persons with COPD are needed.

We developed an automated, Internet-mediated, pedometer-based walking program called Taking Healthy Steps to promote PA in persons with COPD. Taking Healthy Steps combines the Omron HJ-720 ITC pedometer (Omron Healthcare, Inc, Bannockburn, IL, USA) with a disease-specific website accessed via a URL. Taking Healthy Steps provides iterative step-count feedback, individualized step-count goals, education on disease self-management, motivational support, and an online community of social support [22-27]. We studied the efficacy of Taking Healthy Steps in a randomized controlled trial (trial registration: Clinicaltrials.gov NCT01102777) [27]. The conceptual framework, study design, and results at 4 months have been described previously [26,27]. We have shown that Taking Healthy Steps is safe and engaging, and improves health-related quality of life (HRQL) and increases daily step count at 4 months [25-27]. In this study, our primary aim was to assess the long-term efficacy of Taking Healthy Steps on HRQL and daily step counts, a marker for walking behavior change, at 12 months. Our secondary aim was to assess long-term engagement with the PA intervention.

\section{Methods}

\section{Recruitment}

The study design and methods have been reported previously $[26,27]$. Participants were enrolled from national patient care databases of US Veterans, between December 2011 and January 2013, who had received any treatment services in the previous year and had a COPD diagnosis. Zip codes were matched with the Rural Urban Commuting Area Codes to determine whether one's residence was urban or rural [28]. Of the 21 regional Veteran Integrated Service Networks (VISN) across the 50 United States and Puerto Rico, we excluded Veterans from one VISN (VISN-1) where another COPD research study using the Taking Healthy Steps platform was recruiting participants. The coordinating center was located at the Ann Arbor VA Healthcare System, Ann Arbor, MI, USA. Ethical approval for this study was granted by the VA Ann Arbor Healthcare System Human Studies Subcommittee.

A random sample of 28,957 Veterans (half rural, half urban) with a COPD diagnosis was sent a recruitment letter. Inclusion criteria included having access to a computer with an Internet connection, a USB port, and Windows XP, Vista, Windows 7, or Windows 8. Our a priori exclusion criteria excluded those who did not upload baseline step-count data or who did not 
complete the baseline survey to assess HRQL. Per study protocol, participants had to have baseline values for the primary (HRQL) and secondary outcome (daily step count) to be enrolled and randomized. Ultimately, 239 participants were enrolled and randomized in a 2:1 ratio to either Taking Healthy Steps (Internet-mediated, pedometer-based walking program) or wait-list control (pedometer alone), stratified by Modified
Medical Research Council (MMRC) dyspnea score and urban versus rural status (Figure 1). All participants were prompted monthly to report new or worsening medical problems; all self-reported adverse events were recorded. There were no face-to-face encounters with staff; all features were automatically delivered via the website.

Figure 1. CONSORT diagram at 12 months.

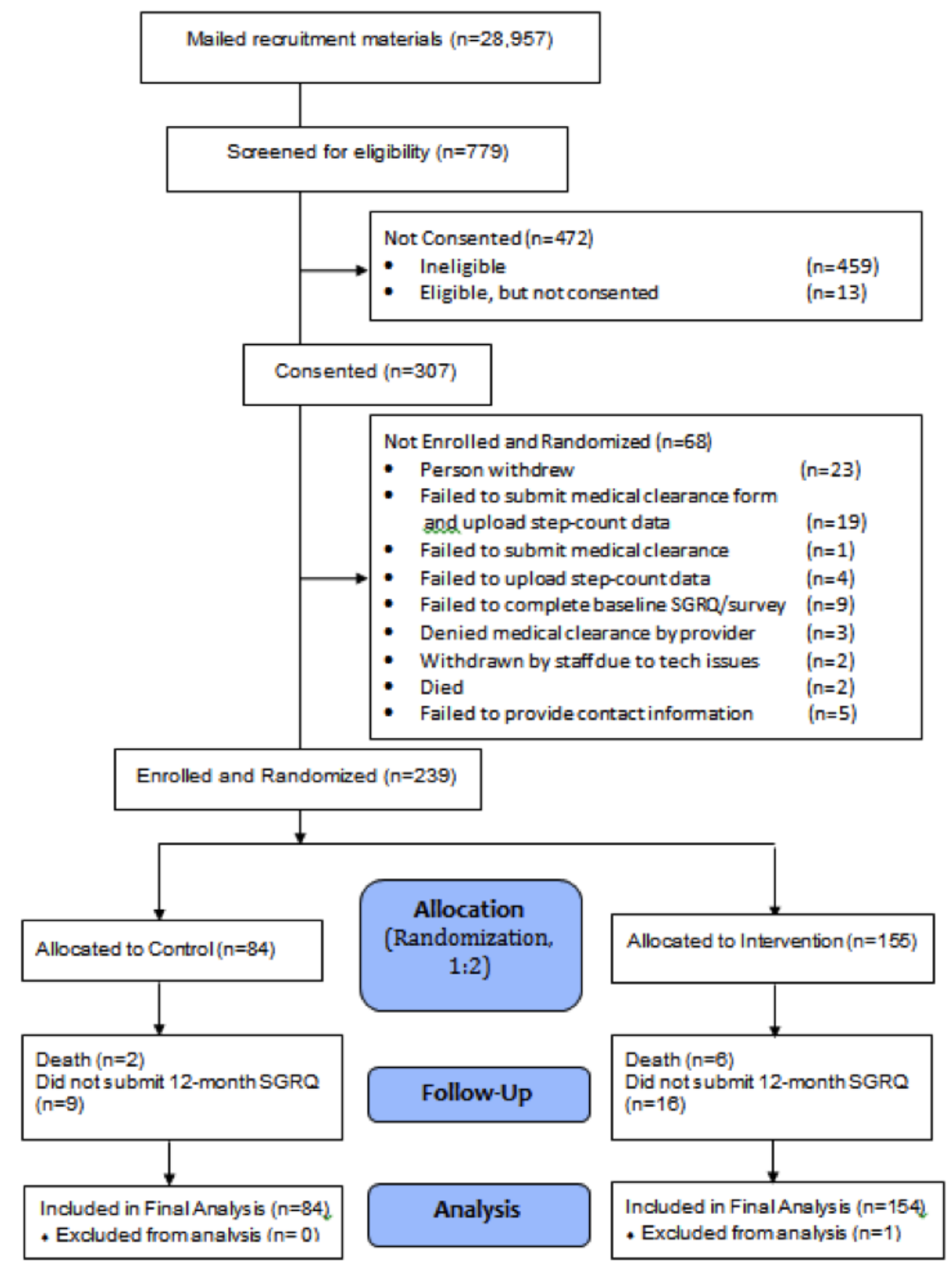

\section{Outcomes}

\section{Primary Outcome}

The St. George's Respiratory Questionnaire (SGRQ), a disease-specific instrument with 50 items that has been well validated in COPD [29,30] was used to assess HRQL. It has a summary total score (SGRQ-TS) composed of three domain scores: symptoms (frequency and severity), activities (that cause or are limited by breathlessness), and impact (social functioning and psychological disturbances resulting from airways disease). Scores range from 0 to 100 with lower scores indicating better HRQL. A change of four units is the minimum clinically important difference for the SGRQ-TS [31]. Study participants completed the SGRQ online at study entry, 4 months, and 12 months.

\section{Secondary Outcome}

Daily step count was assessed by the Omron HJ-720 ITC pedometer. Once participants completed the baseline survey, study staff mailed them a pedometer that had an embedded USB port, an upload cable, and detailed written instructions on how to install the Java software and upload pedometer data. For users who did not have Java already installed on their computers, the software installation was a one-time event. Thereafter, participants uploaded step-count data using the cable that 
connected the pedometer to their home computer. Research staff were available by telephone to assist with software installation and upload of step counts.

A wear day with valid step-count data was defined as one having at least 100 steps and 8 hours of step counts recorded [32]. At baseline, participants wore the pedometer covered with a sticker to blind the participant to device feedback. Baseline daily step count was the mean daily step count calculated using at least 5 days of valid data within a period of seven consecutive days. Follow-up daily step counts were calculated within a window of +/-14 days around day 121 for 4-month values, and $+/-14$ days around day 366 for $12-$ month values. Follow-up daily step counts were the means of at least 5 days of valid data within a period of seven consecutive days. We also calculated the mean daily step count each month by examining the data in 30-day increments. We used values from the last valid week (at least 5 days of valid data within a period of seven consecutive days) in each of those months.

\section{Intervention Group}

Participants randomized to Taking Healthy Steps completed an intensive 4-month intervention period, followed by a distinct 8-month maintenance phase (Table 1). During the first 4 months, participants were instructed to wear the pedometer every day, reminded to upload at least weekly, and were provided access to the website. The website has four key components [26,27]: individualized goal setting was based on uploaded step counts, iterative feedback allowed self-monitoring of step counts, motivational content provided a new educational tip every other day and a new motivational message each week, and an online community forum enhanced social support [22-27]. During the 8-month maintenance phase, participants continued to wear the pedometer, upload daily step counts, receive weekly step-count goals and feedback, and had access to the online community forum. They could view the initial 4 months of educational content and motivational messages, but no longer received new content. Topics on the online community forum included walking in a variety of weather/seasons, health topics (weight management, COPD disease management), injury prevention, barriers to walking, and technical issues with the pedometer and website.

Table 1. Features available to the Taking Healthy Steps and control groups during the first 4 months versus last 8 months of the study.

\begin{tabular}{lllll}
\hline Features & 0-4 Months & & 5-12 Months & \\
& Taking Healthy Steps & Control & Taking Healthy Steps & Control \\
\hline Wear pedometer & Yes & Yes & Yes & Yes \\
Upload step-count data & At least weekly & At least monthly & At least weekly & At least monthly \\
Goal setting & Yes & No & Yes & No \\
Feedback & Yes & No & Yes & No \\
New educational and motivational content & Yes & No & No & No \\
Online community forum & Yes & No & Yes & No \\
\hline
\end{tabular}

\section{Wait-List Control Group}

Participants randomized to the wait-list control group were instructed to wear the pedometer every day, reminded monthly to $\log$ in to the website to upload step-count data, and asked to report all adverse events. Veterans in the wait-list control group received neither instruction to increase PA nor step-count goals. They had access to a webpage that showed only a checklist of surveys completed and a count of what week they were in the study. After 12 months, they were given the option to use the Internet-mediated intervention.

\section{Participant Characteristics, Device Adherence, and Website Engagement}

At baseline, participants answered questions online that assessed comorbidities, oxygen use, smoking status, and demographics. At study entry, 4 months, and 12 months, dyspnea was assessed using the MMRC scale (range 0-4 with 4 indicating the most severe level of dyspnea) [33]. Events self-reported during the study were defined a priori as COPD-related if persons experienced a combination of symptoms and/or required treatment with antibiotics and/or systemic corticosteroids. The COPD-related events included acute exacerbations or pneumonia, ascertained by self-reported events and/or review of health care utilization (hospitalizations and emergency room visits) and pharmacy data. To assure independence of individual acute exacerbations, participants were considered to have experienced a new acute exacerbation only if it were reported 21 or more days after the previous acute exacerbation [34].

We examined device adherence, overall and by group, by calculating the percentage of days (of 366 days) that were wear days with valid step-count data. For the participants who uploaded valid step-count data at 12 months and completed the study, we also examined percentage of days (of 42 days) that were wear days during the last 6 weeks of the study.

In the intervention group, we objectively examined website engagement by recording the number of log-ins to the website by month of study and assessing the frequency of use of the online community forum. In addition, at 4 and 12 months, participants in the Taking Healthy Steps group answered a structured survey eliciting feedback about their commitment to their step-count goals and various aspects of engagement with the intervention, including participants' ease of finding time to $\log$ in to the website, knowledge of step-count goals, and use of the different components of the website. 


\section{Statistical Analysis}

Proportions, means, and standard deviations described baseline participant characteristics. Two-sample $t$ tests and chi-square tests compared baseline characteristics between groups. The occurrence of COPD-related events (acute exacerbations or pneumonia), hospitalizations, emergency room visits, deaths, and adverse events during the study were each compared between groups using a logistic regression model. For the count of hospitalizations, a zero-inflated Poisson regression model was also used to assess the difference in the rate of hospitalizations between groups. These models adjusted for age, gender, treatment group, and oxygen use.

The primary analysis used the intention-to-treat approach, and used a linear mixed-effects model with baseline, 4-month, and 12-month outcome values (eg, SGRQ-TS or daily step count) as dependent variables. No baseline variable was predictive of missingness in models adjusting for stratification variables and treatment group. Thus, the longitudinal data model included participants who had the dependent variable for at least one time point and was expected to give unbiased estimates of the intervention effect assuming missingness at random. The model included participants as random intercepts to adjust for within-participant correlations of repeated measures, fixed predictors of treatment group, 4- and 12-month time indicators, and treatment group by time indicator interactions, MMRC dyspnea score (dichotomized to 0-1 vs 2-4), and urban versus rural residence. We also analyzed the data excluding those who died. The proportion of participants who had at least a 4-unit improvement in SGRQ-TS at 12 months was compared between groups using a chi-square test [31]. For the analysis of mean daily step count by month of study, we used a linear mixed-effect model similar to that for the primary outcome except data were assessed in 30-day increments over the 12-month study period. Predictors were treatment group, month of study as indicator variables (coded as 1-12), group-by-month indicator variables interactions, dichotomized MMRC dyspnea score, and urban versus rural residence.

We assessed website engagement in the intervention group by characterizing the number of log-ins to the website using the mean, median, and interquartile range, and assessed trends over months of study using a linear mixed-effects regression analysis with monthly number of log-ins for each participant as the outcome and time (month since randomization) as the predictor. Trends for device adherence over month of study were examined with percent of days with valid step-count data using a linear mixed-effects model and for use of the online community forum using a generalized mixed-effects model with logit link. The effect of time on participant responses to the online survey about goal commitment and intervention engagement at 4 and 12 months was estimated for each response variable using a mixed-effects model with 4- and 12-month survey data as the dependent variable and predictors including 12-month indicator, baseline dichotomized MMRC dyspnea score, and urban versus rural status. All models, including the model for the number of log-ins, were checked for model assumptions using residuals.

One participant in the Taking Healthy Steps group was considered an outlier given that his change in SGRQ-TS was 4.0 standard deviations greater than the mean for change in SGRQ-TS and his change in daily step count was 8.1 standard deviations greater than the mean for change in daily step count. The extremely high step counts more likely reflected his occupational PA rather than any effects of our intervention. Our main analyses excluded the outlying individual, but we also repeated primary and secondary outcome analyses with this participant included. All analyses were performed with Stata 14.0 (StataCorp LP, College Station, TX, USA).

\section{Results}

\section{Participant Characteristics}

No information is available on the persons to whom we mailed recruitment materials but who were not screened because they did not go to our website and did not call us (Figure 1). The top three reasons for ineligibility of 459 participants were not sedentary $(n=202)$, could not walk a block $(n=120)$, or no compatible computer access $(n=161)$, with some participants having more than one reason (Figure 1). In all, 68 persons consented but were not enrolled and randomized, including 19 who failed to submit a medical clearance form and did not upload step-count data, one who failed to submit a medical clearance form, four who failed to upload step-count data, and nine who failed to complete the baseline SGRQ (Figure 1).

Participants' $(\mathrm{N}=238)$ characteristics include: mean age 67 (SD 9) years, male $(93.7 \%, 223 / 238)$, rural residence $(45.4 \%$, $108 / 238)$, MMRC dyspnea score $\geq 2(30.7 \%, 73 / 238)$, current smokers $(24.8 \%, 59 / 238)$, and supplemental oxygen use $(23.5 \%$, $56 / 238$ ) (Table 2). There were no significant differences in baseline characteristics between study groups, including current smoking history. Overall, 87.8\% (209/238) of participants completed the 12-month online HRQL assessment, and 74.4\% (177/238) uploaded 12-month valid step-count data. In the intervention group, $87.7 \%$ (135/154) of participants completed the HRQL assessment and 76.6\% (118/154) uploaded valid step-count data, compared to $88 \%(74 / 84)$ and $70 \%$ (59/84), respectively, in the control group. 
Table 2. Baseline participant characteristics ( $\mathrm{N}=238)$.

\begin{tabular}{|c|c|c|c|}
\hline Characteristic & Intervention $(\mathrm{n}=154)$ & Control $(n=84)$ & Total $(\mathrm{N}=238)$ \\
\hline Age (years), mean (SD) & $67(8.6)$ & $66.4(9.2)$ & $66.8(8.8)$ \\
\hline Gender (male), n(\%) & $146(94.8)$ & $77(92)$ & $223(93.7)$ \\
\hline \multicolumn{4}{|l|}{ Residence, $\mathbf{n}(\%)$} \\
\hline Urban & $83(53.9)$ & $47(56)$ & $130(54.6)$ \\
\hline Rural & $71(46.1)$ & $37(44)$ & $108(45.4)$ \\
\hline Hispanic $(\mathrm{n}=235), \mathrm{n}(\%)$ & $5(3.3)$ & $1(1)$ & $6(2.6)$ \\
\hline \multicolumn{4}{|l|}{ Race, $n(\%)$} \\
\hline Black & $7(4.6)$ & $3(4)$ & $10(4.2)$ \\
\hline White & $142(92.2)$ & $79(94)$ & $221(92.9)$ \\
\hline Other & $5(3.3)$ & $2(2)$ & $7(2.9)$ \\
\hline Current smoker, n(\%) & $41(26.6)$ & $18(21)$ & $59(24.8)$ \\
\hline Oxygen use, $\mathrm{n}(\%)$ & $35(22.7)$ & $21(25)$ & $56(23.5)$ \\
\hline \multicolumn{4}{|l|}{ SGRQ, ${ }^{a}$ mean $(\mathrm{SD})$} \\
\hline Symptoms & $57.2(19.1)$ & $56(19.9)$ & $56.8(19.3)$ \\
\hline Activities & $62.3(20.2)$ & $64.2(18)$ & $62.9(19.5)$ \\
\hline Impact & $32.2(16.5)$ & $34.1(17.9)$ & $32.9(17)$ \\
\hline Total & $45.6(15.4)$ & $46.8(15.6)$ & $46(15.4)$ \\
\hline Baseline daily step count, mean (SD) & $3488(2316)$ & $3521(2058)$ & $3499(2224)$ \\
\hline \multicolumn{4}{|l|}{ MMRC dyspnea score, ${ }^{\mathbf{b}}$ n (\%) } \\
\hline $0-1$ & $108(70.1)$ & $57(68)$ & $165(69.3)$ \\
\hline $2-4$ & $46(29.9)$ & $27(32)$ & $73(30.7)$ \\
\hline
\end{tabular}

${ }^{\text {a}}$ SGRQ: St. George's Respiratory Questionnaire. Data for symptoms, activities, and impact were available from 236 participants; total from 233 participants.

${ }^{b}$ MMRC: Modified Medical Research Council.

At 12 months, 29 of 238 (12.2\%) participants did not have sufficient data to calculate the SGRQ-TS: 19 Taking Healthy Steps participants and 10 controls. There was no significant difference in baseline SGRQ-TS (mean 49.8, SD 16.1 vs mean 45.6, SD $15.3 ; P=.18$ ) or baseline daily step count (mean 3410 , SD 2667 vs mean 3512, SD 2163; $P=.82$ ) between those for whom SGRQ-TS could not be calculated $(n=29)$ versus those for whom SGRQ-TS was calculated at 12 months $(\mathrm{n}=209)$.

The percent of participants with COPD-related events (acute exacerbations or pneumonia) during the study did not differ between groups (control: 18\%, 15/84; intervention: $22.7 \%$, $35 / 154$; logistic regression OR $1.4,95 \%$ CI $0.7-2.8 ; P=.33$ ). No between-group difference was found in the percent of participants with hospitalizations (control: 17\%, 14/84; intervention: $23.4 \%, 36 / 154$; logistic regression OR 1.6, 95\% CI $0.8-3.2 ; P=.19$ ) or emergency room visits (control: $24 \%$, 20/84; intervention: $29.9 \%, 46 / 154$; logistic regression OR 1.4, $95 \%$ CI $0.8-2.6 ; P=.27)$ during the 12 -month study. For the count of hospitalizations, a zero-inflated Poisson regression model also found no between-group difference. The percent of participants who died during the study did not differ between groups (control: 2\%, 2/84; intervention: 3.9\%, 6/154; $P=.53$ ). Finding no between-group differences in the percentage of participants who were hospitalized or died provided assurance that the censoring of the outcome variables (SGRQ-TS or daily step counts) due to these events was not likely to confound the assessment of the between-group outcome differences. However, we repeated the analyses with deaths excluded as well.

\section{Health-Related Quality of Life}

There was no significant between-group difference in the primary outcome of SGRQ-TS (mean 1.1 units, 95\% CI -2.2 to $4.5 ; P=.50$ ) at 12 months (Table 3 ). The proportion of participants who achieved at least a 4-unit improvement in SGRQ-TS at 12 months was $45.2 \%(61 / 135)$ in the intervention versus $32 \%(23 / 71)$ in the control group $(P=.08)$. There was no significant between-group difference in the SGRQ domain scores of symptoms (mean 0.5 unit, $95 \% \mathrm{CI}-4.2$ to $5.2 ; P=.84$ ), activities (mean 0.04 unit, $95 \% \mathrm{CI}-4.2$ to $4.2 ; P=.99$ ), and impact (mean 2.3 units, $95 \% \mathrm{CI}-1.6$ to $6.1 ; P=.25$ ) at 12 months. 
Table 3. Within-group changes and between-group differences in SGRQ scores and daily step counts at 12 months.

\begin{tabular}{|c|c|c|c|c|c|}
\hline Outcome and arm & $\mathrm{N}$ & $\begin{array}{l}\text { Difference from baseline to } 12 \\
\text { months, } \\
\text { mean }(95 \% \mathrm{CI})\end{array}$ & $P$ & $\begin{array}{l}\text { Between-group difference, } \\
\text { mean }(95 \% \mathrm{CI})\end{array}$ & $P^{\mathrm{a}}$ \\
\hline \multicolumn{6}{|l|}{ SGRQ } \\
\hline Total & & & & $1.1(-2.2,4.5)$ & .50 \\
\hline Taking Healthy Steps & 154 & $-2.5(-4.5,-0.6)$ & .01 & & \\
\hline Control & 84 & $-1.4(-4.1,1.3)$ & .31 & & \\
\hline Symptoms & & & & $0.5(-4.2,5.2)$ & .84 \\
\hline Taking Healthy Steps & 154 & $-3.2(-6.0,-0.4)$ & .02 & & \\
\hline Control & 84 & $-2.7(-6.5,1.1)$ & .16 & & \\
\hline Activities & & & & $0.04(-4.2,4.2)$ & .99 \\
\hline Taking Healthy Steps & 154 & $-1.2(-3.7,1.3)$ & .36 & & \\
\hline Control & 84 & $-1.1(-4.5,2.3)$ & .51 & & \\
\hline Impact & & & & $2.3(-1.6,6.1)$ & .25 \\
\hline Taking Healthy Steps & 154 & $-3.4(-5.6,-1.1)$ & .004 & & \\
\hline Control & 84 & $-1.1(-4.2,2.0)$ & .48 & & \\
\hline Daily step count & & & & $-108(-720,505)$ & .73 \\
\hline Taking Healthy Steps & 154 & $270(-86,626)$ & .14 & & \\
\hline Control & 84 & $163(-336,661)$ & .52 & & \\
\hline
\end{tabular}

a Based on linear mixed-effect models, adjusting for group, 4- and 12-month indicators, group xtime indicator interactions, baseline MMRC dyspnea score (dichotomized to $0-1$ vs 2-4), and urban versus rural status.

Intervention participants showed an improvement in SGRQ-TS of a mean 2.5 units $(95 \% \mathrm{CI}-4.5$ to -0.6$)$ at 12 months, compared to baseline $(P=.01)$ (Table 3). For domain scores in the intervention group, symptoms improved by a mean 3.2 units (95\% CI -6.0 to $-0.4, P=.02)$, and impact improved by a mean 3.4 units $(95 \% \mathrm{CI}-5.6$ to $-1.1, P=.004)$ at 12 months. The control group showed no significant changes in the SGRQ-TS and domain scores at 12 months compared to baseline (Table 3 ). When the analysis was repeated with the outlying individual included, no substantive difference was seen in results, except improvement in symptoms within the Taking Healthy Steps group was marginally significant $(P=.05)$. When the analysis excluded the eight deaths, results remained nearly identical.

\section{Daily Step Count}

There was no significant difference between groups with respect to the secondary outcome of daily step count at 12 months
$(P=.73)$ (Table 3$)$. There was no significant change in daily step count in the intervention participants $(P=.14)$ or in the control group $(P=.52)$ at 12 months, compared to baseline (Table 3 ). Examination of daily step count by month of intervention showed that differences in daily step counts in the intervention group compared to controls were maximal and statistically significant at month 4 , but approached zero in months 8 to 12 (Figure 2). Between-group $P$ values were $<.001$ at 4 months, .28 at 8 months, and .82 at 12 months. Within the intervention group, although daily step counts peaked at 2 months and then declined over the course of the study, daily step counts continued to be higher than baseline values in all months of the study (Figure 2). Analysis including the outlying individual showed improvement in daily step counts at 12 months to be significant in the Taking Healthy Steps group $(P=.048)$. Analysis excluding the eight deaths did not change results. 
Figure 2. Mean daily step count and 95\% confidence intervals by month of study. Note: the Taking Healthy Steps (THS) curve is shifted to the right of the control curve on the $\mathrm{x}$-axis for ease of visual display. Baseline data are included at month zero.

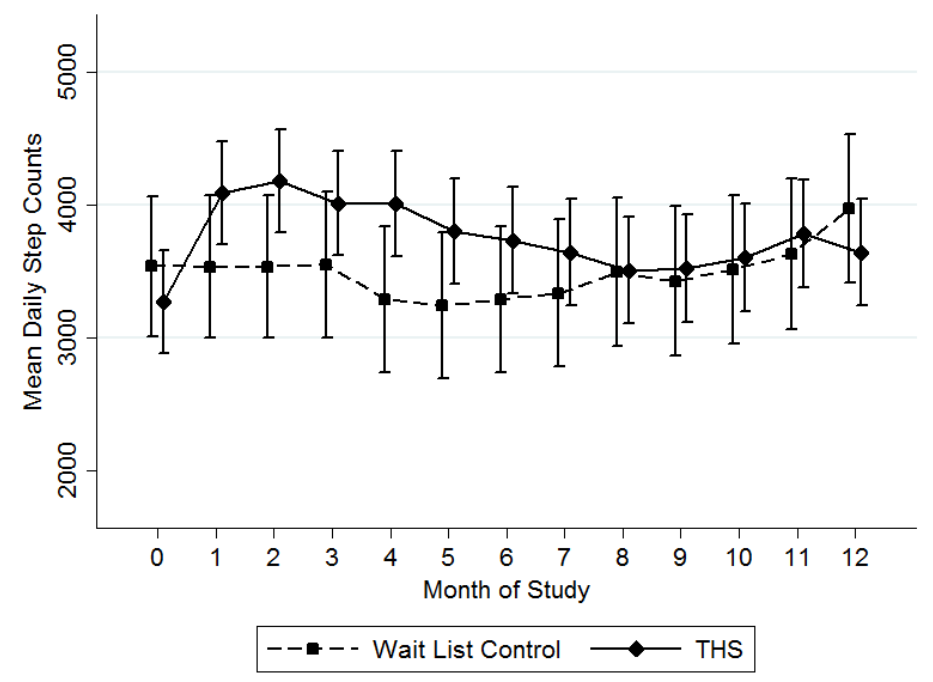

\section{Device Adherence and Website Engagement}

Device adherence during the 12-month study period was significantly higher in the intervention group than the control group, with mean $76.7 \%$ (SD 29.5) of the 366 days having valid step-count data in the intervention group versus mean $63.7 \%$ (SD 32.9) of the 366 days having valid step-count data in the control group $(P=.002)$. For the 177 participants in both groups who uploaded valid step-count data at 12 months and completed the study, mean $83.1 \%$ (SD 21.9) of days in the last 6 weeks of the study had valid step-count data. In these last 6 weeks, mean $87.5 \%$ (SD 16.5) of days had valid step-count data in the intervention group, which was significantly higher than the mean $74.1 \%$ (SD 28.1) of days observed in the control group $(P<.001)$. In the intervention group, device adherence decreased significantly over time $(P<.001)$, with mean $92.1 \%(95 \% \mathrm{CI}$ 86.6-97.6) of days having valid step-count data at month 1 versus $70.3 \%$ (95\% CI 64.9-75.8) of days at month 12 (Figure 3).

In the intervention group, mean number of log-ins to the website decreased significantly over the months of study $(P<.001$; Figure 4). The number of monthly log-ins was mean 6.8 (SD 3.7; median 6, IQR 3) at month 1, which declined to mean 4.2 (SD 3.5; median 4, IQR 3) by month 9 and mean 3.0 (SD 3.0; median 3 , IQR 5) by month 12 (Figure 4). In the intervention group, $83.8 \%(129 / 154)$ of the participants used the online community forum at some point during the 12-month study; $66.2 \%$ $(102 / 154)$ of participants directly viewed an online community forum thread or entry, and an additional $17.5 \%$ (27/154) of participants posted a new topic or a reply at least once. More than half of the participants responded "definitely true" (22/121, $18.2 \%)$ or "mostly true" $(45 / 121,37.2 \%)$ to the statement: "I learned helpful information when I used the online community forum." There was a significant trend for decreasing use of the online community forum by month of study $(P<.001)$.

Responses to questions regarding participant's goal commitment were not significantly different at 12 months compared to 4 months (Table 4). When asked, "Overall, how motivated are you to walk each day?" with responses from $1=$ not motivated and $10=$ extremely motivated, the mean response was 6.8 (SD 2.3 ) at 4 months compared to mean 6.5 (SD 2.5) at 12 months $(P=.06)$. Responses to questions about engagement with the use of Taking Healthy Steps were not significantly different at 12 months compared to 4 months (Table 4). 
Table 4. Goal commitment and engagement with Taking Healthy Steps intervention.

\begin{tabular}{|c|c|c|c|c|}
\hline Goal commitment and engagement & $\mathrm{N}^{\mathrm{a}}$ & $\begin{array}{l}4 \text { months } \\
\text { mean }(95 \% \mathrm{CI})\end{array}$ & $\begin{array}{l}12 \text { months } \\
\text { mean }(95 \% \mathrm{CI})\end{array}$ & $P^{\mathrm{b}}$ \\
\hline \multicolumn{5}{|l|}{ Goal commitment $^{c}$} \\
\hline It's hard to take my step-count goal seriously. & 147 & $2.1(1.9-2.2)$ & $2.0(1.9-2.2)$ & .69 \\
\hline Quite frankly, I don't care if I reach my step goal or not. & 147 & $1.7(1.6-1.8)$ & $1.7(1.6-1.8)$ & .46 \\
\hline I am strongly committed to pursuing my step-count goal. & 146 & $3.8(3.6-4.0)$ & $3.7(3.5-3.9)$ & .52 \\
\hline It wouldn't take much to make me abandon my step-count goal. & 147 & $1.9(1.7-2.1)$ & $2.0(1.8-2.2)$ & .27 \\
\hline I think my step-count goal is a good goal to shoot for. & 146 & $4.0(3.8-4.2)$ & $3.9(3.8-4.1)$ & .77 \\
\hline \multicolumn{5}{|l|}{ Engagement in Taking Healthy Steps ${ }^{\mathrm{d}}$} \\
\hline $\begin{array}{l}\text { I would recommend the Taking Healthy Steps walking program to another } \\
\text { person with COPD. }\end{array}$ & 146 & $1.3(1.2-1.4)$ & $1.2(1.1-1.3)$ & .01 \\
\hline It was easy for me to find the time to log in to the website once a week. & 146 & $1.8(1.6-2.0)$ & $1.8(1.6-2.0)$ & .92 \\
\hline $\begin{array}{l}\text { I had technical difficulty uploading step-count data from the pedometer } \\
\text { to my computer. }\end{array}$ & 146 & $4.0(3.7-4.2)$ & $3.9(3.7-4.1)$ & .75 \\
\hline I knew what my step goal should be every day. & 147 & $1.5(1.4-1.6)$ & $1.5(1.4-1.6)$ & .48 \\
\hline I was able to comfortably increase my daily step count every week. & 147 & $2.6(2.5-2.8)$ & $2.8(2.6-3.0)$ & .10 \\
\hline I looked at the graphs of the step counts that I walked. & 147 & $1.6(1.4-1.7)$ & $1.6(1.4-1.7)$ & .76 \\
\hline The motivational messages and educational tips were easy to understand. & 143 & $1.9(1.8-2.0)$ & $1.8(1.7-1.9)$ & .21 \\
\hline I learned helpful information when I used the online community forum. & 137 & $2.5(2.3-2.7)$ & $2.4(2.3-2.6)$ & .52 \\
\hline The daily step-count goals were too high for me to walk each day. & 147 & $3.4(3.2-3.5)$ & $3.4(3.2-3.5)$ & .98 \\
\hline
\end{tabular}

${ }^{a}$ Participants with responses at 4 and/or 12 months were included in the models.

${ }^{\mathrm{b}}$ Based on linear mixed-effect models with 4 and 12 months as the dependent variable and predictors of 12-month indicator, intervention group indicator and baseline MMRC dyspnea score (dichotomized to 0-1 vs 2-4) and urban versus rural status.

${ }^{\mathrm{c}}$ Response scale $1-5$ with $1=$ strongly disagree, $2=$ disagree, $3=$ neither agree nor disagree, $4=$ agree, $5=$ strongly agree.

${ }^{\mathrm{d}}$ Response scale $1-5$ with $1=$ definitely true, $2=$ mostly true, $3=$ not sure, $4=$ mostly false, $5=$ definitely false.

Figure 3. Percentage and $95 \%$ confidence intervals of days with valid step-count data in the intervention group by month of study.

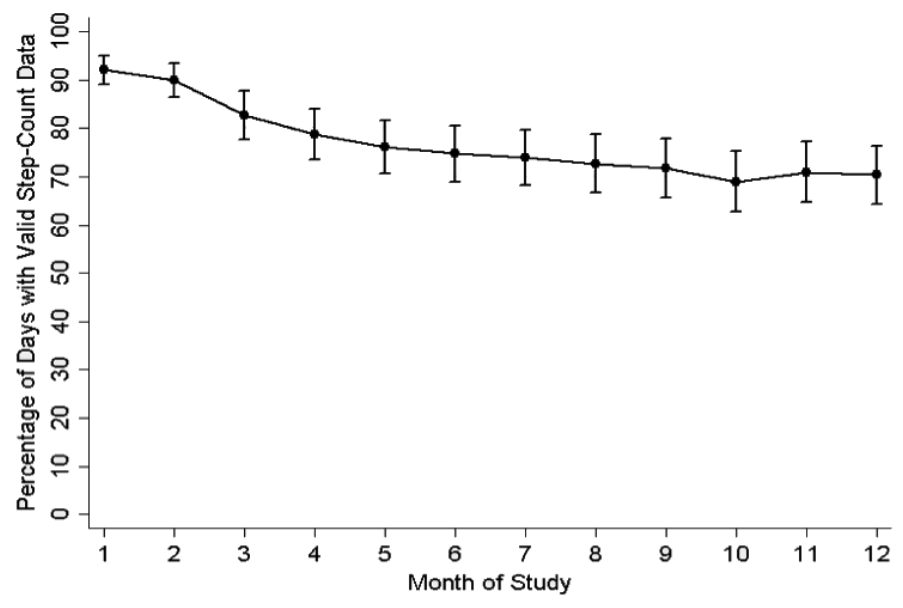


Figure 4. Mean log-ins and 95\% confidence intervals in the intervention group by month of study.

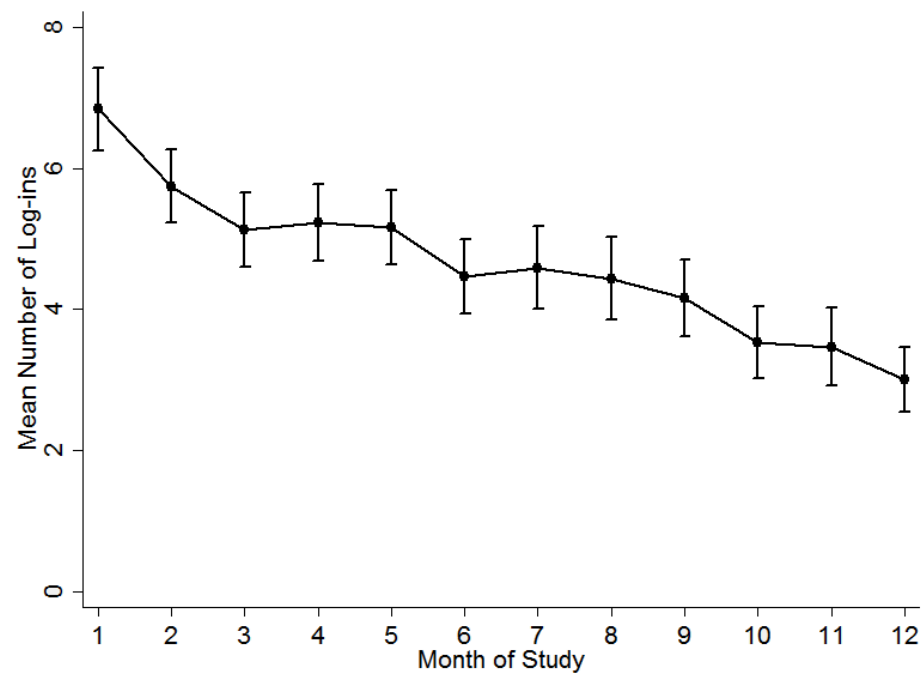

\section{Safety}

Adverse events were categorized as pulmonary, cardiac, musculoskeletal, or other. A significantly greater percent of participants in the intervention group $(27.9 \%, 43 / 154)$ had minor musculoskeletal adverse events than in the control group (10\%, $8 / 84 ; P<.001)$. There were no differences between groups with respect to pulmonary, cardiac, or other adverse events during the 12 months.

\section{Discussion}

We show that our Internet-mediated, pedometer-based walking intervention does not maintain benefits in HRQL and daily step counts at 12 months, despite demonstrated improvements at 4 months [27]. Although we report negative findings for the study overall, lessons learned about device adherence and website engagement are highly informative for guiding the development of future PA interventions that can effectively promote long-term behavior change and sustain PA.

Overall, we found that a COPD population found the study feasible and were engaged. The percentage of participants who completed the 12-month study, providing HRQL and step-count data, was high. In addition, our objective results assessing device adherence and showing that $83 \%$ of days for participants in both groups within the last 6 weeks of the study had valid step-count data support that people were not lost to the study and then showing up for the last evaluation period. Importantly, persons in the intervention group had significantly higher device adherence compared to the control group for the study overall and at the end of the study. This finding supports that the goal setting, feedback, educational and motivational content, and online community forum provided on the website significantly increased intervention engagement beyond that observed with the use of a pedometer alone.

For the first time, we rigorously elicited participant survey responses about goal commitment and intervention engagement, and objectively assessed device adherence and website engagement during the 12-month study. In the intervention group, responses to questions about engagement at 12 months were the same compared to those at 4 months, with participants finding time to $\log$ in to the intervention, knowing their step-count goal, and using the graphs, tips and messages, and forums. They also reported that they were as committed to their step-count goal at 12 months as they were at 4 months. Although participants reported the same levels of goal commitment and intervention engagement at the end of the study compared to the beginning of the study, sustained behavior change was not observed because there were significant decreases in number of days with valid step-count data, number of log-ins to the website, and use of the online community forum over time. Although we can only speculate as to cause and effect, the decrease in daily step count (a marker of intervention efficacy and walking behavior change) over time mirrors the declines in device adherence and website engagement over time.

The reasons for the observed decline in daily step counts over time require further exploration. Participants may not have continued to wear the pedometer, log in to the website, and walk over the 12 months for a variety of possible reasons that we did not assess, such as waning interest with the intervention, progression of underlying COPD, flare-up of comorbidities, or occurrence of intercurrent life events (eg, spouse illness). The effect of the intervention on daily step counts could potentially have been greater if the control group had not received a pedometer and monthly reminders to upload step counts. We are confident that battery life did not affect the results because we mailed a new battery with replacement instructions to each participant every 4 months. We replaced lost or broken devices reported to us.

These results are similar to published data examining maintenance exercise programs after conventional pulmonary rehabilitation [16-21]. Typically, the unstable clinical course of a chronic lung disease such as COPD makes it difficult for patients to resume or maintain an exercise program [20]. Although we observed no difference in the number of COPD-related events, such as acute exacerbations, between groups, the occurrence of acute exacerbations and flare-up of comorbidities over a period of 12 months may have modified 
the response to Taking Healthy Steps within the intervention group.

The failure to obtain long-term benefits with our PA interventions parallels the literature studying other behavior changes, such as smoking cessation [35] and weight loss [36]. Our 8-month maintenance phase retained the key components of goal setting, feedback, and social support. The main feature omitted beginning at month 5 was new educational and motivational content. These findings support that ongoing behavioral modification techniques are critical to sustain PA $[37,38]$. We speculate that additional intervention components, such as face-to-face contact with peers and/or health care providers, would enhance the social support and motivation needed to sustain PA as a routine behavior. Use of evolving technology, such as wireless transmission and mobile connectivity with cell phones, smartphones/mobile phones, or tablets, could potentially provide anytime/anywhere access to the PA intervention and enhance its long-term efficacy $[37,39,40]$. Intensive counseling and support at the time of acute exacerbations and flare-up of comorbidities would address medical barriers to PA and motivate patients to continue to walk after an illness. Finally, incorporating the health care provider, health care institutions, communities, and society at large into PA interventions could enhance long-term behavior change and adherence to effectively sustain PA in persons with COPD $[41,42]$.

The exact role of digital walking programs in starting and maintaining exercise in persons with COPD remains to be determined. Both acute and chronic models of digital walking programs are potentially useful. Acute intervention models are needed to initiate and promote PA in the vast majority of patients with COPD who cannot access a conventional pulmonary rehabilitation program [43]. In addition, maintenance models are appropriate and much needed because long-term maintenance of behavior change is challenging. In addition, digital walking programs can potentially be useful adjuncts after conventional pulmonary rehabilitation to maintain benefits, which start to wane as early as 3 to 6 months after program completion [20,21]. They can also be an important component of COPD self-management programs [44]. An interesting future question to address is whether restarting our intervention every 4 to 8 months would be an efficacious long-term strategy.

The potential full impact of our intervention can only be appreciated by performing a future cost-effectiveness analysis. Results from cross-sectional data from our group and others have shown that every step counts. We have not found a "threshold" or "optimal" daily step count to obtain clinical benefits. The benefits appear to be linear such that those with higher step counts have lower risks for acute exacerbations, hospitalizations, hospital admissions and readmissions, and death compared to those with lower step counts [9-14]. Future work is needed to examine whether PA interventions such as ours can decrease health care resource utilization and result in cost savings to our health care system.

Major strengths of our study include the randomized controlled trial design with balanced groups at baseline, objective data on device adherence and website engagement, and the long-term follow-up of 12 months. Our intervention is based on a theoretical model, and informed by previous work eliciting patient feedback to optimize user acceptability and develop the motivational and educational content [25,45]. Our Internet-mediated, pedometer-based intervention focuses specifically on walking, a low-intensity PA that most patients can do. It has already been shown that a greater quantity of low-intensity PA reduces risk of COPD hospitalizations, whereas high-intensity PA does not result in risk reduction [15].

Our study has several limitations. We studied primarily white male Veterans limiting the generalizability of our results. Spirometric confirmation of the COPD diagnosis was not made at study entry. However, any potential misclassification of asthma as COPD was most likely balanced between groups and would not bias the primary results. The vast majority of the patients had MMRC $<2$. It is justified to include patients with MMRC $<2$ because patients with newly diagnosed COPD have reduced PA even at the earliest stages of the disease [3]. It is important to promote PA even when patients are not significantly symptomatic, as recommended by the GOLD guidelines for COPD [6]. We found no difference in benefit of the PA intervention in those with MMRC $<2$ versus MMRC $\geq 2$. We acknowledge the final response rate was likely biased toward responders who had a particular interest in this type of intervention, and the results may not be generalizable to a wider COPD population. Finally, seasonal variation can influence our secondary outcome of daily step counts. We minimized the impact of season by having a 12-month intervention and enrolling participants over all four seasons.

An Internet-mediated, pedometer-based PA intervention for persons with COPD does not maintain improvements in HRQL or daily step count at 12 months, despite demonstrated improvements at 4 months. In addition, waning engagement with the PA intervention support that future efforts should focus on improving features of PA interventions to enhance long-term behavior change and sustain engagement with PA. These findings need to be considered when designing future Internet-mediated PA interventions.

\section{Acknowledgments}

We thank the Veterans for their participation in this research study. The study was funded by Department of Veterans Affairs, Health Services Research and Development Service (Grant IIR 09-366, Richardson); Department of Veterans Affairs, Rehabilitation Research and Development Service (Career Development Award, F6847W, Moy); and NIH National Heart, Lung and Blood Institute (Grant T32 HL007749-20, Martinez). None of the funding bodies had any role in the design, collection, analysis or interpretation of the data, in writing the manuscript, or in the decision to submit the manuscript for publication. 


\section{Authors' Contributions}

MLM, RK, HQN, MDC, DEG, NDG, and CRR were involved in the conception and design of all stages of the study. MLM, CHM, RK, PR, HQN, MDC, and CRR were involved in study data collection. CHM, HMK, RK, PR, RGH, and NDG conducted study analyses. All authors read and approved the final manuscript. CRR, the study PI, had full access to all the data in the study and takes responsibility for the integrity of the data and the accuracy of the data analysis.

\section{Conflicts of Interest}

None declared. This study was initiated by the investigators, who do not receive any financial support from Omron Healthcare. The results of this study do not constitute endorsement of the Omron pedometer by the authors.

\section{Multimedia Appendix 1 \\ CONSORT-EHEALTH checklist.}

[PDF File (Adobe PDF File), 786KB-Multimedia Appendix 1]

\section{References}

1. Moy ML, Danilack VA, Weston NA, Garshick E. Daily step counts in a US cohort with COPD. Respir Med 2012 Jul;106(7):962-969 [FREE Full text] [doi: 10.1016/j.rmed.2012.03.016] [Medline: 22521225]

2. Waschki B, Kirsten AM, Holz O, Mueller K, Schaper M, Sack A, et al. Disease progression and changes in physical activity in patients with chronic obstructive pulmonary disease. Am J Respir Crit Care Med 2015 Aug 1;192(3):295-306. [doi: 10.1164/rccm.201501-00810C] [Medline: 26020495]

3. Van Remoortel H, Hornikx M, Demeyer H, Langer D, Burtin C, Decramer M, et al. Daily physical activity in subjects with newly diagnosed COPD. Thorax 2013 Oct;68(10):962-963 [FREE Full text] [doi: 10.1136/thoraxjnl-2013-203534] [Medline: 23604460]

4. Hurst JR, Vestbo J, Anzueto A, Locantore N, Müllerova H, Tal-Singer R, Evaluation of COPD Longitudinally to Identify Predictive Surrogate Endpoints (ECLIPSE) Investigators. Susceptibility to exacerbation in chronic obstructive pulmonary disease. N Engl J Med 2010 Sep 16;363(12):1128-1138. [doi: 10.1056/NEJMoa0909883] [Medline: 20843247]

5. Pitta F, Troosters T, Probst VS, Spruit MA, Decramer M, Gosselink R. Physical activity and hospitalization for exacerbation of COPD. Chest 2006 Mar;129(3):536-544. [doi: 10.1378/chest.129.3.536] [Medline: 16537849]

6. Vestbo J, Hurd SS, Agustí AG, Jones PW, Vogelmeier C, Anzueto A, et al. Global strategy for the diagnosis, management, and prevention of chronic obstructive pulmonary disease: GOLD executive summary. Am J Respir Crit Care Med 2013 Feb 15;187(4):347-365. [doi: 10.1164/rccm.201204-0596PP] [Medline: 22878278]

7. McNamara RJ, McKeough ZJ, McKenzie DK, Alison JA. Physical comorbidities affect physical activity in chronic obstructive pulmonary disease: a prospective cohort study. Respirology 2014 Aug;19(6):866-872 [FREE Full text] [doi: 10.1111/resp.12325] [Medline: 24909412]

8. Divo M, Cote C, de Torres JP, Casanova C, Marin JM, Pinto-Plata V, et al. Comorbidities and risk of mortality in patients with chronic obstructive pulmonary disease. Am J Respir Crit Care Med 2012 Jul 15;186(2):155-161. [doi: 10.1164/rccm.201201-0034OC] [Medline: 22561964]

9. Moy M, Gould M, Liu I, Lee J, Nguyen H. Physical activity assessed in routine care predicts mortality after a COPD hospitalization. ERJ Open Res [in press] 2016 Sep 01 (forthcoming).

10. Moy ML, Teylan M, Danilack VA, Gagnon DR, Garshick E. An index of daily step count and systemic inflammation predicts clinical outcomes in chronic obstructive pulmonary disease. Ann Am Thorac Soc 2014 Feb;11(2):149-157. [doi: 10.1513/AnnalsATS.201307-2430C] [Medline: 24308588]

11. Moy ML, Teylan M, Weston NA, Gagnon DR, Danilack VA, Garshick E. Daily step count is associated with plasma C-reactive protein and IL-6 in a US cohort with COPD. Chest 2014 Mar 1;145(3):542-550. [doi: 10.1378/chest.13-1052] [Medline: 24091482]

12. Moy ML, Teylan M, Weston NA, Gagnon DR, Garshick E. Daily step count predicts acute exacerbations in a US cohort with COPD. PLoS One 2013;8(4):e60400 [FREE Full text] [doi: 10.1371/journal.pone.0060400] [Medline: 23593211]

13. Nguyen HQ, Chu L, Amy LI, Lee JS, Suh D, Korotzer B, et al. Associations between physical activity and 30-day readmission risk in chronic obstructive pulmonary disease. Ann Am Thorac Soc 2014 Jun;11(5):695-705. [doi: 10.1513/AnnalsATS.201401-0170C] [Medline: 24713094]

14. Waschki B, Kirsten A, Holz O, Müller K, Meyer T, Watz H, et al. Physical activity is the strongest predictor of all-cause mortality in patients with COPD: a prospective cohort study. Chest 2011 Aug;140(2):331-342. [doi: 10.1378/chest.10-2521] [Medline: 21273294]

15. Donaire-Gonzalez D, Gimeno-Santos E, Balcells E, de Batlle J, Ramon MA, Rodriguez E, PAC-COPD Study Group. Benefits of physical activity on COPD hospitalisation depend on intensity. Eur Respir J 2015 Nov;46(5):1281-1289. [doi: 10.1183/13993003.01699-2014] [Medline: 26206873] 
16. Brooks D, Krip B, Mangovski-Alzamora S, Goldstein RS. The effect of postrehabilitation programmes among individuals with chronic obstructive pulmonary disease. Eur Respir J 2002 Jul;20(1):20-29 [FREE Full text] [Medline: 12166571]

17. Griffiths TL, Burr ML, Campbell IA, Lewis-Jenkins V, Mullins J, Shiels K, et al. Results at 1 year of outpatient multidisciplinary pulmonary rehabilitation: a randomised controlled trial. Lancet 2000 Jan 29;355(9201):362-368. [Medline: $\underline{10665556]}$

18. Ringbaek T, Brondum E, Martinez G, Thogersen J, Lange P. Long-term effects of 1-year maintenance training on physical functioning and health status in patients with COPD: A randomized controlled study. J Cardiopulm Rehabil Prev 2010;30(1):47-52. [doi: 10.1097/HCR.0b013e3181c9c985] [Medline: 20068423]

19. Beauchamp MK, Evans R, Janaudis-Ferreira T, Goldstein RS, Brooks D. Systematic review of supervised exercise programs after pulmonary rehabilitation in individuals with COPD. Chest 2013 Oct;144(4):1124-1133. [doi: 10.1378/chest.12-2421] [Medline: 23429931]

20. Ries AL, Kaplan RM, Myers R, Prewitt LM. Maintenance after pulmonary rehabilitation in chronic lung disease: a randomized trial. Am J Respir Crit Care Med 2003 Mar 15;167(6):880-888. [doi: 10.1164/rccm.200204-3180C] [Medline: 12505859]

21. Spencer LM, Alison JA, McKeough ZJ. Maintaining benefits following pulmonary rehabilitation: a randomised controlled trial. Eur Respir J 2010 Mar;35(3):571-577 [FREE Full text] [doi: 10.1183/09031936.00073609] [Medline: 19643944]

22. Richardson CR, Buis LR, Janney AW, Goodrich DE, Sen A, Hess ML, et al. An online community improves adherence in an internet-mediated walking program. Part 1: results of a randomized controlled trial. J Med Internet Res 2010;12(4):e71 [FREE Full text] [doi: 10.2196/jmir.1338] [Medline: 21169160]

23. Richardson CR, Mehari KS, McIntyre LG, Janney AW, Fortlage LA, Sen A, et al. A randomized trial comparing structured and lifestyle goals in an internet-mediated walking program for people with type 2 diabetes. Int J Behav Nutr Phys Act 2007;4:59 [FREE Full text] [doi: 10.1186/1479-5868-4-59] [Medline: 18021411]

24. Moy ML, Janney AW, Nguyen HQ, Matthess KR, Cohen M, Garshick E, et al. Use of pedometer and Internet-mediated walking program in patients with chronic obstructive pulmonary disease. J Rehabil Res Dev 2010;47(5):485-496 [FREE Full text] [Medline: 20803392]

25. Moy ML, Weston NA, Wilson EJ, Hess ML, Richardson CR. A pilot study of an Internet walking program and pedometer in COPD. Respir Med 2012 Sep;106(9):1342-1350 [FREE Full text] [doi: 10.1016/j.rmed.2012.06.013] [Medline: 22795984]

26. Martinez CH, Moy ML, Nguyen HQ, Cohen M, Kadri R, Roman P, et al. Taking Healthy Steps: rationale, design and baseline characteristics of a randomized trial of a pedometer-based Internet-mediated walking program in veterans with chronic obstructive pulmonary disease. BMC Pulm Med 2014;14:12 [FREE Full text] [doi: 10.1186/1471-2466-14-12] [Medline: 24491137]

27. Moy ML, Collins RJ, Martinez CH, Kadri R, Roman P, Holleman RG, et al. An Internet-mediated pedometer-based program improves health-related quality-of-life domains and daily step counts in COPD: a randomized controlled trial. Chest 2015 Jul;148(1):128-137. [doi: 10.1378/chest.14-1466] [Medline: 25811395]

28. Weeks WB, Kazis LE, Shen Y, Cong Z, Ren XS, Miller D, et al. Differences in health-related quality of life in rural and urban veterans. Am J Public Health 2004 Oct;94(10):1762-1767. [Medline: 15451747]

29. Jones PW, Quirk FH, Baveystock CM, Littlejohns P. A self-complete measure of health status for chronic airflow limitation. The St. George's Respiratory Questionnaire. Am Rev Respir Dis 1992 Jun;145(6):1321-1327. [doi: 10.1164/ajrccm/145.6.1321] [Medline: 1595997$]$

30. Kaplan RM, Ries AL, Reilly J, Mohsenifar Z, National Emphysema Treatment Trial Research Group. Measurement of health-related quality of life in the national emphysema treatment trial. Chest 2004 Sep;126(3):781-789. [doi:

10.1378/chest.126.3.781] [Medline: 15364757]

31. Jones PW. St. George's Respiratory Questionnaire: MCID. COPD 2005 Mar;2(1):75-79. [Medline: 17136966]

32. Matthews CE, Hagströmer M, Pober DM, Bowles HR. Best practices for using physical activity monitors in population-based research. Med Sci Sports Exerc 2012 Jan;44(1 Suppl 1):S68-S76 [FREE Full text] [doi: 10.1249/MSS.0b013e3182399e5b] [Medline: 22157777]

33. Mahler DA, Wells CK. Evaluation of clinical methods for rating dyspnea. Chest 1988 Mar;93(3):580-586. [Medline: 3342669]

34. Aaron SD, Fergusson D, Marks GB, Suissa S, Vandemheen KL, Doucette S, Canadian Thoracic Society/Canadian Respiratory Clinical Research Consortium. Counting, analysing and reporting exacerbations of COPD in randomised controlled trials. Thorax 2008 Feb;63(2):122-128. [doi: 10.1136/thx.2007.082636] [Medline: 17702790]

35. Jiménez-Ruiz CA, Andreas S, Lewis KE, Tonnesen P, van Schayck CP, Hajek P, et al. Statement on smoking cessation in COPD and other pulmonary diseases and in smokers with comorbidities who find it difficult to quit. Eur Respir J 2015 Jul;46(1):61-79. [doi: 10.1183/09031936.00092614] [Medline: 25882805]

36. Appel LJ, Clark JM, Yeh H, Wang N, Coughlin JW, Daumit G, et al. Comparative effectiveness of weight-loss interventions in clinical practice. N Engl J Med 2011 Nov 24;365(21):1959-1968 [FREE Full text] [doi: 10.1056/NEJMoa1108660] [Medline: 22085317]

37. Sallis R, Franklin B, Joy L, Ross R, Sabgir D, Stone J. Strategies for promoting physical activity in clinical practice. Prog Cardiovasc Dis 2015;57(4):375-386. [doi: 10.1016/j.pcad.2014.10.003] [Medline: 25459975] 
38. Wilson JJ, O'Neill B, Collins EG, Bradley J. Interventions to increase physical activity in patients with COPD: a comprehensive review. COPD 2015 Jun;12(3):332-343. [doi: 10.3109/15412555.2014.948992] [Medline: 25221907]

39. Verwey R, van der Weegen S, Spreeuwenberg M, Tange H, van der Weijden T, de Witte L. A pilot study of a tool to stimulate physical activity in patients with COPD or type 2 diabetes in primary care. J Telemed Telecare 2014 Jan;20(1):29-34. [doi: 10.1177/1357633X13519057] [Medline: 24414397]

40. Tabak M, Brusse-Keizer M, van der Valk P, Hermens H, Vollenbroek-Hutten M. A telehealth program for self-management of COPD exacerbations and promotion of an active lifestyle: a pilot randomized controlled trial. Int J Chron Obstruct Pulmon Dis 2014;9:935-944 [FREE Full text] [doi: 10.2147/COPD.S60179] [Medline: 25246781]

41. Heath GW, Parra DC, Sarmiento OL, Andersen LB, Owen N, Goenka S, Lancet Physical Activity Series Working Group. Evidence-based intervention in physical activity: lessons from around the world. Lancet 2012 Jul 21;380(9838):272-281. [doi: 10.1016/S0140-6736(12)60816-2] [Medline: 22818939]

42. Spruit MA, Pitta F, McAuley E, ZuWallack RL, Nici L. Pulmonary rehabilitation and physical activity in patients with chronic obstructive pulmonary disease. Am J Respir Crit Care Med 2015 Oct 15;192(8):924-933. [doi: 10.1164/rccm.201505-0929CI] [Medline: 26161676]

43. Rochester CL, Vogiatzis I, Holland AE, Lareau SC, Marciniuk DD, Puhan MA, ATS/ERS Task Force on Policy in Pulmonary Rehabilitation. An official American Thoracic Society/European Respiratory Society policy statement: enhancing implementation, use, and delivery of pulmonary rehabilitation. Am J Respir Crit Care Med 2015 Dec 1;192(11):1373-1386. [doi: 10.1164/rccm.201510-1966ST] [Medline: 26623686]

44. Effing TW, Vercoulen JH, Bourbeau J, Trappenburg J, Lenferink A, Cafarella P, et al. Definition of a COPD self-management intervention: International Expert Group consensus. Eur Respir J 2016 Jul;48(1):46-54. [doi: 10.1183/13993003.00025-2016] [Medline: 27076595]

45. Danilack VA, Weston NA, Richardson CR, Mori DL, Moy ML. Reasons persons with COPD do not walk and relationship with daily step count. COPD 2014 Jun;11(3):290-299. [doi: 10.3109/15412555.2013.841670] [Medline: 24152213]

\title{
Abbreviations
}

AE: acute exacerbations

COPD: chronic obstructive pulmonary disease

FEV ${ }^{1}$ : forced expiratory volume in 1 second

GOLD: Global Initiative for Chronic Obstructive Lung Disease

HRQL: health-related quality of life

MMRC: Modified Medical Research Council

PA: physical activity

SGRQ: St George's Respiratory Questionnaire

SGRQ-TS: St George's Respiratory Questionnaire Total Score

VISN: Veteran Integrated Service Network

\author{
Edited by G Eysenbach; submitted 09.02.16; peer-reviewed by N Cobb, I Muller, G Jerome, D Ryan, R Grainger, T Poder; comments \\ to author 10.03.16; revised version received 21.04.16; accepted 24.05.16; published 08.08.16 \\ Please cite as: \\ Moy ML, Martinez CH, Kadri R, Roman P, Holleman RG, Kim HM, Nguyen HQ, Cohen MD, Goodrich DE, Giardino ND, Richardson \\ $C R$ \\ Long-Term Effects of an Internet-Mediated Pedometer-Based Walking Program for Chronic Obstructive Pulmonary Disease: \\ Randomized Controlled Trial \\ J Med Internet Res 2016;18(8):e215 \\ URL: http://www.jmir.org/2016/8/e215/ \\ doi: $10.2196 /$ jmir.5622 \\ PMID: 27502583
}

CMarilyn L Moy, Carlos H Martinez, Reema Kadri, Pia Roman, Robert G Holleman, Hyungjin Myra Kim, Huong Q Nguyen, Miriam D Cohen, David E Goodrich, Nicholas D Giardino, Caroline R Richardson. Originally published in the Journal of Medical Internet Research (http://www.jmir.org), 08.08.2016. This is an open-access article distributed under the terms of the Creative Commons Attribution License (http://creativecommons.org/licenses/by/2.0/), which permits unrestricted use, distribution, and reproduction in any medium, provided the original work, first published in the Journal of Medical Internet Research, is properly cited. The complete bibliographic information, a link to the original publication on http://www.jmir.org/, as well as this copyright and license information must be included. 